\title{
Algumas Observações sobre as Vermischte Bermerkungen ${ }^{1}$
}

\author{
Bento Prado Júnior \\ Universidade Federal de São Carlos
}

resumo Este trabalho visa mostrar que as Vermischte Bemerkungen não ocupam lugar marginal na obra de Wittgenstein. Pelo contrário, constituiriam, com as reflexões sobre cultura, arte e religião, uma chave essencial para a compreensão do núcleo lógico ou gramatical dessa filosofia. Para além das notórias transformações ou diferentes fases da ou na concepção da linguagem, poderiam também dar a ver algo como uma profunda continuidade do pensamento ou da obra de Wittgenstein. 0 caráter essencialmente indireto da linguagem e do trabalho da filosofia, entre a prosa e a poesia, estaria no coração do pensamento de Wittgenstein ao longo de toda sua obra e seria indispensável mesmo para a compreensão das transformações por que foi obrigado a passar ao longo das décadas.

palavras-chave linguagem - arte - religião - expressão

"Wir kämpfen mit der Sprache.

Wir stehen im Kampf mit der Sprache"

(Wittgenstein, 1931)

"Lutar com palavras

é a luta mais vã.

Entanto lutamos

mal rompe a manhã."

(Carlos Drummond de Andrade, antes de 1942)

Recebido em 15 de dezembro de 2005. Aceito em 06 de março de 2006.

Tradução: Raquel de Almeida Prado (texto originalmente escrito em francês).

doispontos, Curitiba, São Carlos, vol. 3, n. 1, p.11-36, abril, 2006 
Vou limitar-me a comentar algumas frases de Wittgenstein, extraídas de um livro aparentemente periférico em sua obra. Trata-se das Vermischte Bemerkungen ${ }^{2}$, onde G.H. von Wright e H. Nyman reuniram as considerações do filósofo acerca de cultura, das artes e da religião, ao longo de sua vida, que lhes pareceram as mais notáveis. Mesmo considerando, como é necessário, a filosofia da linguagem - lógica ou gramática - como o centro da obra, esses textos, aparentemente marginais, não deixam, contudo, de fornecer uma preciosa chave para a compreensão do que há de mais central no pensamento de Wittgenstein: - na linguagem de Guimarães Rosa, seu estrito caroço.

Mesmo antes do Tractatus (quanto a isso não parece haver mudanças ao longo da obra ${ }^{3}$ ) o valor é inobjetivável. Segundo a curiosa formulação de Conferência sobre a Ética: "Quanto a isso, só posso descrever meu sentimento ${ }^{4}$ através de uma metáfora: se um homem pudesse escrever um livro de Ética que fosse realmente um livro de Ética, esse livro destruiria, como numa explosão, todos os outros livros do mundo". Só podemos, a propósito, produzir metáforas - aquilo que importa jamais poderia ser objeto de um livro, não pode caber dentro de um livro; caso fosse introduzido num livro haveria de destruí-lo implodindo todas as bibliotecas do planeta. Indizível, inapreensível pela escrita (que é necessariamente "objetivante”), a Ética sempre conservará, para Wittgenstein a posição privilegiada de télos do pensamento 5 , como a parte "não escrita e principal do Tractatus". Mas a Ética, implicando o mundo dos valores, envolve o todo da Cultura e sua impossibilidade como teoria implica a impossibilidade de uma Kulturwissenschaft. Sem ciência ou teoria da cultura, ou seja, sem Estética e sem Ética (mas também sem Teologia...) - sempre logicamente impossíveis - ainda resta um lugar para os aforismos que falam, de maneira oblíqua, da arte e da moral (lembremos Merleau-Ponty e sua idéia da natureza indireta da linguagem, que está no horizonte ou para além de todo uso objetivante da linguagem). Mas, sobretudo, esse discurso inevitavelmente metafórico é necessariamente impregnado pela experiência vivida da decadência. O que transparece claramente em um texto de 1949, onde podemos ler: "meu próprio pensamento sobre a arte e os valores é muito mais desiludido do que poderia ser aquele dos 
homens de há cem anos. O que, aliás, não quer dizer que o meu seja mais correto. Quer simplesmente dizer que, no primeiro plano de meu pensamento, aparecem fenômenos de decadência, o que, justamente, não era o caso deles"6.

\section{II}

Já estamos, pois, no cerne de nossa questão. E, para melhor esclarecê-la, leiamos um parágrafo originalmente destinado ao prefácio das Philosophische Bemerkungen. Esse texto (1930) merece ser lido com muita atenção. Começa com a seguinte declaração: "Este livro foi escrito para aqueles que têm afinidade com o espírito no qual foi escrito"7. O que não é pouca coisa e que esclarece o páthos catastrofista do autor, um pouco à maneira do Rousseau dos Dialogues que começava explicando-se para o leitor contemporâneo, necessariamente pouco sensível, nos seguintes termos: "Je m'en expliquerai: mais ce sera prendre le soin le plus inutile ou le plus superflu: car tout ce que je vous dis ne sauroit être entendu que par ceux à qui l'on n'a pas besoin de le dire 8 ". Há, contudo, uma diferença; enquanto Rousseau voltase para o futuro, na esperança de um leitor por vir, finalmente liberto da miséria sócio-cultural do presente, Wittgenstein parece querer voltar-se para um passado perdido para sempre, do qual restam, apenas, no presente, uns poucos espíritos que lhe são solidários.

E Wittgenstein situa esse espírito raro nos tempos em que vivemos: “É um espírito que, creio eu, não é o mesmo que o da civilização européia e americana. O espírito dessa civilização, do qual a indústria, a arquitetura, música, fascismo e socialismo de nosso tempo são a expressão, é estranho ao autor, que não simpatiza com ele" 9 .

A matéria dessa observação é claramente o presente imediato e, através dele, o espírito único que se exprime em todas as formas de vida (formas simbólicas ou sociais): ciência, economia, religião, política e arte. Trata-se de identificar a alma contemporânea, sua fisionomia, de fazer o diagnóstico da doença que lhe corrompe o coração e nos cerca, como uma bruma espessa, por todos os lados. Diagnosticar a crise ou essa doença já é iniciar sua terapia: ver claramente o que nos cerca permite um trabalho sobre si mesmo que pode chegar até um interlocutor eventual ${ }^{10}$. Trata-se, a partir 
daí, de realizar uma conversão do olhar que pode nos libertar da atmosfera que nos envenena. Mas eis que já nos encontramos diante do paradoxo surpreendente que nos cabe iluminar: após o diagnóstico da decadência, Wittgenstein acrescenta: "Isto não é um juízo de valor".

Manifestar antipatia não significa desqualificar, como se as diferentes formas de vida, que não podem deixar de partilhar o mesmo plano mundano, não fossem susceptíveis de uma hierarquia justificada por algum valor supra-mundano. E Wittgenstein explica: "Isto não é um juízo de valor. Não como se eu ignorasse que o que hoje se apresenta como arquitetura não é arquitetura e o que se chama de música moderna não merecesse, de minha parte, uma grande desconfiança (embora sem compreender sua linguagem), mas o desaparecimento das artes não justifica nenhum juízo depreciativo em relação a uma determinada humanidade" 11 .

Wittgenstein se explica, mas, pelo menos aparentemente, parece mergulhar-nos em plena aporia. De fato, como descrever uma decadência, enumerando seus deméritos e os horrores que nos causam, sem juízo de valor? Uma resposta é imediatamente esboçada: "Pois em tal época, justamente, as naturezas autênticas e fortes se afastam do domínio das artes para se voltarem para outras coisas, e o valor do indivíduo, de uma forma ou de outra, consegue expressar-se"12. Numa palavra: o fim das artes deixa, num nível diferente, intacta a autenticidade e a força de uma humanidade, que no entanto devemos reconhecer como empobrecida.

Mas o problema continua o mesmo. $\mathrm{Na}$ esperança de resolvê-lo, parecenos estratégico tentar esclarecer essa idéia dificil de uma humanidade que é decadente, sem nada perder de sua força e de sua autenticidade, ou seja, de sua própria humanidade. Para chegar a tanto, precisamos examinar como Wittgenstein retoma e transforma de maneira original o lugar comum da crítica da Europa, do "Amerikanismus" ou da "decadência do ocidente". A idéia não é nova - desnecessário retroceder até Rousseau, bastando lembrar a gênese da Kulturkampf na Alemanha ou, entre outros, os discursos dos primeiros eslavófilos do início do século XIX, antes de Soloviev ${ }^{13}$. Ou mesmo - que escândalo! - Tocqueville que, num dos momentos mais sombrios e proféticos de La Démocratie en Amérique, pensa na possibilidade da emergência futura, nesse país, de uma aristocracia do dinheiro, bem pior do que a antiga, já que insensível à honra e à cultura ${ }^{14}$. 
Porém, mesmo que Wittgenstein tenha sido, desde sempre, sensível a essa temática, o que importa é compreender sua complexa relação com Spengler, cujo nome está inscrito (ao lado de Boltzmann, Hertz, Schopenhauer, Frege, Russell, Kraus, Loos, Weininger e Sraffa) entre os autores que o influenciaram. O próprio Wittgenstein não deixa de interrogar-se a respeito da relação entre sua própria reflexão teórica e a de Spengler, apontando ao mesmo tempo para o abismo que as separa e o indiscutível parentesco que as une.

Essa relação não é uma simples identificação ou filiação: ela permite uma ruptura radical. Mas para melhor evidenciar essa ruptura, é preciso descrever o background de continuidade que poderia ser definido, para usar a linguagem de Lukács, como aquele de um espírito anti-capitalista romântico. Inimigo da Aufklärung, um espírito que só vê, na sociedade industrial presente, a morte da arte e o desencanto do Mundo Esse espírito está resumido no esboço de prefácio das Philosophische Bemerkungen que aqui nos serve tanto de ponto de partida como de horizonte. Wittgenstein aí afirma: "Que eu seja compreendido ou apreciado pelo cientista ocidental típico, isso não me importa, pois ele não compreende o espírito no qual escrevo"15. Dezesseis anos mais tarde, a oposição parece ter atingido o paroxismo. No fim da Segunda guerra Mundial, Wittgenstein denuncia o "filistinismo" dos pacifistas que exigem a supressão da bomba atômica. Não poderíamos ver na bomba atômica - que paradoxo! - algo como um remédio, mesmo se amargo? Quase como um mal necessário? E Wittgenstein acrescenta: "Pois tudo o que sou capaz de pensar a esse respeito, é que a bomba nos faz entrever o fim, a destruição desse mal horrível, dessa repugnante água de lavagem que é a ciência"16.

Mas, para além da convergência no diagnóstico catastrofista, Wittgenstein destaca sua distância com relação a Spengler. O que aparece como positivo no autor de O Declínio do Ocidente é o seu método comparativo. Mas "ele seria melhor compreendido" ou "se expressaria melhor", se a comparação entre diferentes períodos culturais fosse esclarecida pela idéia de "ar de família" (o texto é de 1931). Senão, e esse é o equívoco de Spengler, "tudo o que vale para o paradigma da teoria será julgado válido, volens nolens, para o objeto a respeito do qual se faz a teoria; e 'sempre o será..."17. A idéia de um "ar de família" indissociável da idéia de método comparativo (ou de "visão sinóptica"18) funciona aqui como o instru- 
mento de combate contra o objetivismo, o universalismo ou o essencialismo clássicos. Toda a filosofia dos anos 30 e 40 ("visão de aspecto", etc...) parece estar presente in nuce nessa reserva manifestada face a Spengler em 1931. Mas também em perfeita continuidade (complicando o problema da discriminação das "filosofias" de Wittgenstein - $1^{\mathrm{a}}$ e $2^{\mathrm{a}}, 1^{\mathrm{a}}, 2^{\mathrm{a}}$ e $3^{\mathrm{a}}$...) com um aspecto do Tractatus, a saber, a escolha implícita de "ser perspectivista sem ser relativista", retomando a frase definitiva de Luis Henrique Lopes dos Santos $^{19}$. O que Wittgenstein diz aqui contra uma pretensa Kulturwissenschaft e o objetivismo metafisico que ela implica, misturando paradigma (Urbild) e objeto, já não era dito no Tractatus a respeito da mecânica newtoniana? Com efeito, a proposição 6.342 terminava com a seguinte frase: "Assim, também nada diz sobre o mundo a possibilidade de descrevê-lo por meio da mecânica newtoniana; mas diz algo sobre ele a possibilidade de que seja descrito por meio dela precisamente como vem a ser o caso. E também diz algo sobre o mundo a possibilidade de descrevê-lo mais simplesmente por meio de uma mecânica que por meio de outra". É claro que a mecânica newtoniana, como ciência, opõe-se claramente a uma pseudo-Kulturwissenschaft, mas nem por isso podemos confundir, em seu domínio próprio, rigorosamente científico, o paradigma ou o modelo teórico com seu objeto. Com efeito, em sua estrutura circular, o Tractatus neutraliza o caráter aparentemente positivo ou dogmático ${ }^{20}$ da ontologia das proposições em 1 revelando ao leitor o estilo apofático do discurso filosófico; com efeito, a última proposição ${ }^{21}$ recai sobre e neutraliza, nuança a primeira, transformando-a no início de um argumento de natureza transcendental - isto é, como um raciocínio que descreve como devem ser o mundo, a linguagem e suas inter-relações para ser possível enunciar proposições verdadeiras ou falsas a respeito dos eventos em geral, transformando a filosofia numa simples forma de mostrar e não de dizer.

Mas em que sentido é possível um perspectivismo sem relativismo ou uma ontologia apofática sem ceticismo? Qual é a diferença entre a proposição 6.324 do Tractatus e o "convencionalismo moderado" de Poincaré? Ou ainda, qual é a diferença entre a idéia wittgensteiniana da multiplicidade dos jogos de linguagem e o pragmatismo (pensemos no exemplo de Rorty)? Para começar, nem o convencionalismo parece impor-nos a contradição entre "conteúdo proposicional" e "estilo de enunciação" presente na convergência entre as seguintes proposições: “a 
ciência é uma nauseabunda água de lavagem" e "isto não é um juízo de valor". Mas devemos deixar de lado o convencionalismo que se instala no campo da epistemologia e nos afastaria, assim, de nosso problema. Enfrentemos apenas a questão do pragmatismo. Não é verdade que a filosofia de Wittgenstein é freqüentemente classificada como uma forma de pragmatismo (ou até mesmo de behaviorismo "lingüístico")? Não há dúvida que as idéias de jogo de linguagem e de forma de vida abrem espaço para um privilégio da práxis ou da ação. Assim, em Über Gewissheit (nota 402 de 19 de 3 de 1951), depois de tentar descrever a dialética que une proposições de forma empírica às pseudo-proposições de base, Wittgenstein, getrost (mais tranqüilo, por assim dizer) retoma a frase do Fausto de Goethe: "No princípio era a ação". Mas dois dias depois acrescenta: "Quero assim dizer algo que soa como pragmatismo. // Uma espécie de Visão do Mundo vem aqui me atropelar"'22.

Wittgenstein opõe assim, claramente, seu pensamento ao pragmatismo como uma Weltanschauung, isto é como uma transgressão dos limites do pensamento, digamos uma espécie de ideologia. Mas há certamente várias formas de apropriação pragmatista da obra de Wittgenstein. De acordo com Rorty, por exemplo, com a última filosofia de Wittgenstein e sua idéia da prática dos jogos de linguagem, teríamos retomado a Via Real descoberta pelo pragmatismo norte-americano. $\mathrm{O}$ que significaria, antes de mais nada, eliminar em sua base o mito da Verdade, da adaequatio, da filosofia como contemplação da coisa-em-si ou como retorno extático à esfera do acesso pré-linguístico ao Ser, mais velhos que a práxis ou que a existência social dos homens. Valendo-se de Wittgenstein (e de muitos outros autores, é claro), Rorty coloca, no lugar da adaequatio ${ }^{23}$, a idéia de re-descrição. Re-descrever é, também, uma maneira de mudar nossa vida, mudando a visão que dela temos. A verdade é da ordem da poíesis - um fazer, uma produção - e não da ordem da alétheia, da descoberta ou da revelação. $\mathrm{O}$ mundo não está nunca, em si mesmo, pronto e acabado, esperando que abramos os olhos para encetar nossa inspecção especulativa, nossa contemplatio. Muito pelo contrário, está, é ou existe em função de nossos consensos ou de nossas práticas eficientes, numa espécie de darwinismo epistemológico-prático. Haveria então tantas verdades e valores quanto formas de vida viáveis. O que significaria que, com Rorty, Protágoras se desagrava de Platão. Contudo, não mais será possível evitar 
uma desastrosa conseqüência da escolha do pragmatismo. Com efeito, se o pragmatismo nos proíbe todo juízo de valor cujo fundamento seja transcendente (que não se apoiaria no único chão verdadeiro de nossas práticas eficientes), somos obrigados, queiramos ou não, a guardar um valor: $o$ valor de sobrevivência. Restar-nos-ia, assim, algo como um valor quase-objetivo que, todavia, não teria cabimento para Wittgenstein, pois nos proibiria de ter saudades de uma forma de vida já morta ou passada que são tão importantes na definição de sua atitude.

Voltemos, pois, a Wittgenstein e aos textos das Vermischte Bemerkungen, mas, desta vez, com a ajudo do livro $A$ Viena de Wittgenstein, de Toulmin e Janik $^{24}$. Esse livro nos mostra as raízes das idéias de Wittgenstein sobre a arte e a ética na cultura vienense da virada do século ${ }^{25}$ (raízes às quais seus discípulos ingleses e norte-americanos foram freqüentemente pouco sensíveis, não lhes reconhecendo a devida importância). Podemos então perguntar-nos se as reflexões algo melancólicas de Wittgenstein não se devem, em grande medida, ao fim dessa cultura (a vienense), à queda do Império e à ascensão do nazismo.

Não se pode negar que, nos textos que se seguem ao fim da segunda guerra mundial, ainda se encontra a expressão de uma nostalgia do mundo anterior à guerra de 14-18. Também é verdade que o pequeno número de leitores aos quais se dirige são aqueles contemporâneos que ainda respiram a atmosfera de um mundo desaparecido. Mas é igualmente inegável que a idéia de cultura e de valor já está definida desde o início, que ela precede a queda do Império e, a fortiori, as transformações do pensamento post-Tractatus. E mais, é evidente que, desde sempre, Wittgenstein situa o fim da cultura no meio do século XIX. Não é necessário voltar ao detalhe do texto, já citado, de 1948, em que Wittgenstein se queixa da miséria cultural que os homens de cem anos atrás não podiam sentir.

Homens de cem anos atrás? 1848? Não cabe aqui dramatizar; basta lembrar que o Gründerzeit e o salto para a frente da industrialização da velha Áustria situam-se na segunda metade do século XIX, com a instituição de uma sólida burguesia que, como no caso da família de Wittgenstein, ao lado de seus empreendimentos industriais, atribuía a si mesma o papel de mecenas das Artes e da Cultura. Tudo se passa como se, para Wittgenstein, o percurso da Grande Cultura (em particular a literatura de língua alemã) estivesse estritamente definido entre o Sturm und Drang e 
Schopenhauer ou o fim do romantismo. O texto seguinte, datado de 1929, é crucial: "Eu me pergunto amiúde se meu ideal cultural é novo, ou seja, se é contemporâneo, ou se remonta à época de Schumann. Pareceme, pelo menos, que é a continuação desse ideal - de uma outra continuação, quero dizer, que não aquela que ocorreu efetivamente na história. Assim, fica excluída a segunda metade do século XIX”26

Que tal período da história esteja "no primeiro plano" da reflexão de Wittgenstein é o que vem a confirmar esta Bemerkung de 1947: "Talvez um dia dessa civilização ${ }^{27}$ uma cultura surgirá./ / Haverá então uma história verdadeira dos séculos 18,19, 20, que será do maior interesse"28.

\section{III}

Ninguém ignora a importância da revolução conceitual operada na passagem dos anos 20 para os anos 30 que põe abaixo o edificio do Tractatus. Poderíamos descrevê-la, se tivéssemos espaço para tanto, com a ajuda de um livro publicado apenas no Brasil sob o título de Fenomenologia em Wittgenstein; Tempo, Cor e Figuração ${ }^{29}$ por meu colega e homônimo Bento Prado Neto. Poderíamos ver assim como, nas Philosophische Bemerkungen, o projeto de completar o Tractatus descrevendo a aplicação da lógica, que o primeiro livro deixava de lado, culmina no abandono da idéia da possibilidade de uma análise completa da linguagem (particularmente com a descoberta do abismo que separa o tempo vivido do tempo físico homogêneo, à maneira de Bergson ${ }^{30}$, que proíbe instituir uma linguagem fenomenológica de base). Precisamos contentar-nos em assinalar esse corte para ver melhor, em contra-ponto, o que há de contínuo na reflexão sobre a cultura e os valores, do começo até o fim da obra.

O corte é nítido entre duas concepções da linguagem. Passamos do império ou da onipresença da forma geral da proposição para a dispersão dos jogos de linguagem em sua multiplicidade e heterogeneidade. São as idéias de sentido e de uso do Tractatus, que mudam de sentido. E, no entanto, o télos da atividade filosófica permanece o mesmo: mudar a vida de maneira a tornar possível a ataraxia. No quadro do Tractatus, esse télos aparece nas proposições 6.521 e 6.522 sobre o "Místico"31. Depois de 1930 não se pode mais manter, tal e qual, a oposição entre dizer e mostrar que sofrem 
profunda metamorfose e, sobretudo, a idéia de uma apreensão do mundo sub specie aeterni como totalidade limitada (Cf. proposição 6.45: "A apreensão do mundo sub specie aeterni é sua apreensão como totalidade limitada./ / O sentimento do mundo como totalidade limitada é o Místico"). Sob o fundo de um "perspectivismo aprofundado" - que jamais, repitamos, se transforma em relativismo -, essa totalização do olhar, dum olhar tornado errante, não mais é possível (como é impossível a totalização da linguagem através da universalidade da forma lógica).

Poderíamos dizer que passamos aqui do Durchsehen ao Übersehen do "ver através" á visão de conjunto ou sinóptica. A "visibilidade" muda de sentido assim como a proposição "nada está escondido" ou a idéia de que nenhum véu se interpõe entre nós e as coisas. Como para Hegel, quando contornamos a cortina que nos separa das coisas em si, descobrimos que nada há por trás da cortina; mas estamos longe da dialética, pois é o mundo da experiência quotidiana (o que está na cara...) que se revela à conversão filosófica. Numa palavra, a linguagem ordinária não mais se superpõe a uma forma lógica a ser desencavada pela análise completa. Num trocadilho que faz alusão ao título de uma obra de Freud, poderíamos dizer: "análise completa, análise interminável". O que nosso olhar deve ver (por assim dizer, "de cima"32 ou quase "de fora") é nosso uso da língua ou nosso jogo de linguagem, guiado por uma espécie de "variação imaginária", por efeito de "comparação", de sua estrutura, das regras que a governam: - imagine um tribo cuja linguagem... É preciso saber parar em filosofia, nos diz Wittgenstein, mas não mais se pode "jogar a escada" e apreender o Místico sub specie aeterni. Mas há um aforismo de 1948 que klingt als as proposições sobre o Místico. É aquele em que Wittgenstein escreve: "Quando filosofamos, precisamos mergulhar no antigo Caos e lá sentirmo-nos bem"33.

É preciso, aqui, ousar uma interpretação dessa bela e misteriosa frase. Fazer filosofia seria descer do sistema de proposições possíveis num jogo de linguagem, na direção do aglomerado pré-proposicional das regras ou da "mitologia' que está em sua base? Caos seria igual ao Abgrund em que "repousa" o jogo de linguagem 34 ? Talvez pudéssemos dizer que para filosofar precisamos distanciar-nos um pouco das regras que nos governam, descer de algum modo até um espaço que as precede. $\mathrm{O}$ caótico não corresponderia exatamente ao que precede as 
regras? Algo com um espaço pré-humano da humanidade onde se instalam as diferentes humanidades particulares? Para passar de um jogo de linguagem a outro (o que é sempre possível, mesmo se implica alguma violência ${ }^{35}$ a contrapelo do universalismo fácil de Apel e Habermas) não seria necessário entrever, não o kosmos como totalidade limitada, mas o Caos subjacente 36 ?

Mas parece que a mudança não modifica essencialmente a contrapartida ética (ou a concepção da Arte e da Cultura). No Tractatus (proposição $6.43^{37}$ ) estava dito que a Vontade podia mudar as fronteiras do mundo, mas nunca os fatos, o dizível. Ou seja, as fronteiras do mundo podem se tornar mais largas ou mais estreitas na medida em que o querer for bom ou mau. Não teria esta oposição a mesma forma daquela, descrita em datas muito diferentes nas Vermischte Bemerkungen entre as formas de vida ricas ou privadas de cultura? Dizer que descrever uma Civilização como nauseabunda não é um juízo de valor não seria um pouco como afirmar que um homem infeliz não é menos homem que o feliz?

Não seria possível dizer - repitamos - que o mesmo horizonte abriga tanto a proposição do Tractatus quanto a oposição entre formas de vida ricas ou pobres de cultura? Se os juízos de valor são proibidos, podemos, em compensação, apreciar a capacidade expressiva de diferentes usos da linguagem. Diferentes usos da linguagem - num mesmo jogo de linguagem ou entre jogos diferentes - podem ser igualmente regulares (nenhum jogo deixa de sê-lo) e comportar graus bem diferentes de expressividade, de capacidade metafórica ou sugestiva. A diferença que os separa é que um deles permite fazer ver de outra maneira o mundo ou aquilo que sempre esteve aí, diante de nós; numa diferença derivada do trabalho sobre si que deve estar presente nos trabalhos do arquiteto e do filósofo ${ }^{38}$, que pode ou deve beneficiar o interlocutor levando-o à mesma conversão: a ascese do filósofo é um trabalho sobre si que torna possível sua aplicação terapêutica (do mesmo modo que, na psicanálise, a auto-análise é condição da análise de outrem). A idéia de expressão, ao contrário do que diz Hans-Johann Glock em seu Dicionário Wittgen$\operatorname{stein}^{39}$, não tem apenas o sentido "negativo", que Ryle atribuiria à palavra avowal, que visa o uso de sentenças psicológicas construídas em primeira pessoa e no presente do indicativo, que carecem de sentido. Certamente as palavras Äusserung e Ausdruck têm, no vocabulário de 
Wittgenstein, um uso que remete ao mero comportamento, algo de prélingüístico que proíbe a idéia de uma linguagem privada. Mas remetem, também, para além de qualquer oposição entre mundo interno e mundo externo, privado ou público, para o poder da linguagem, especialmente em seu uso artístico, esse poder de tornar visível o que está diante de nós e que se escondera por efeito das câimbras da alma ou das distorções de nossa forma de vida.

Para dar um passo à frente, tomemos a liberdade de fazer uma aproximação pouco comum entre Wittgenstein e... Descartes(!), que é de hábito opor sob todos os aspectos. De um lado, a idéia cartesiana de constância da "quantidade de pensamento" (simétrica à constância da "quantidade de movimento"), de outro, a idéia da constância de "força e de autenticidade" em todas as formas de vida (e em todos os indivíduos). Com efeito, do lado de Wittgenstein, está claro que as diferentes formas de vida (como os indivíduos) exprimem-se segundo estilos diferentes, como é o caso da oposição entre o gênio ${ }^{40}$ e o simples honnête homme. É exatamente isso que é dito explicitamente com a seguinte metáfora de Wittgenstein na passagem dos anos 30 aos 40: “O gênio não é mais iluminado do que qualquer outro homem honesto, mas concentra essa luz, graças a uma espécie de lente, num ponto ardente" 41 ; do mesmo modo, a respeito da relação entre o homem normal e o louco, Wittgenstein diz em 1946 que "Não é necessário olhar a loucura como uma doença. Por que não como uma mudança súbita de personalidade - mais ou menos súbita" 42 . Do lado de Descartes, também, o filósofo, não dispõe de mais "luz natural"43 que o homem comum mas, graças ao método (sua lente, que lhe permite dividir ${ }^{4}$ ou analisar as idéias confusas, por assim dizer) pode fazer eclodir a luz, a clareza e a distinção das idéias simples.

Mas retornemos uma vez mais à Vermischte Bemerkungen que é o objeto essencial de nosso cuidado nesta circunstância. Se a Cultura está morrendo, é porque a Arte e a Religião praticadas hoje não nos levam mais a medirmo-nos com os limites da linguagem, a chocarmo-nos contra eles, única forma de percebê-los, porque é apenas excepcionalmente que podemos descer até o Urchaos para trazer de lá alguns indícios, algumas conchas nunca vistas, na impossibilidade total de trazer de lá proposições. Um pouco como a mosca que aprende a sair da garrafa, depois de tantos choques contra suas paredes internas. Mas os dois movimentos 
(para cima, em direção do gargalo da garrafa, ou "para baixo", em direção do Caos arcaico) são o mesmo movimento que percorre a vida que, atingindo o limite do dizível, dá lugar à emergência da Cultura. Em uma palavra, a experiência da dificuldade de expressão à qual Wittgenstein se refere freqüentemente (sempre de maneira complexa, jamais fazendo psicologia ${ }^{45}$, como na seguinte reflexão em que usa uma metáfora tomada de empréstimo de Kraus: "Parece-me às vezes que já estou filosofando com a boca desdentada e que falar com a boca desdentada me parece a maneira autêntica, a melhor maneira de falar. Encontro em Kraus algo semelhante. Ao invés de reconhecer nisso uma decadência"46.

Para melhor delimitar nosso problema, seria preciso passar pelos textos sobre a religião. Mas falta-nos o tempo necessário e é melhor entrar diretamente nos capítulos essenciais da música e da tragédia, que ocupam tanto espaço nas Vermischte Bemerkungen ${ }^{47}$, mesmo que tenhamos de fazêlo de maneira sumária. No tratamento de tais questões (se for permitida tal entrée en matière), Wittgenstein opõe-se, como Adorno, ao Presente, mas o faz, obviamente, de modo muito diferente. Nada mais distante das notas sobre a música das Vermischte Bemerkungen do que A Filosofia da Nova Música. Vanguardista literário (entusiasta dos escritos de Karl Kraus, mais do que da poesia de Rilke, contra o juízo de Heidegger), Wittgenstein tinha um gosto estético-musical mais tradicionalista do que o pensador de Frankfurt: ou seja, a de um nostálgico do romantismo. Como já vimos, tudo acabou com Schumann.

Convém reiterar o já dito: nessa coleção aparentemente heteróclita de juízos (melhor dizendo, de aforismos) sobre a música, a literatura e a religião, tais formas de expressão são todas reduzidas ${ }^{48}$ ao conteúdo ético dos estilos de vida que estão em sua base. Tudo se passa como se o cristianismo (despojado de sua coroa paulina e institucional49, assim como da idéia do Além) e a música romântica expressassem o mesmo. Uma experiência solitária semelhante àquela que se manifesta na obra de Tolstoi ${ }^{50}$ ? Wittgenstein, um narodnik solitário ou individualista? $\mathrm{O}$ privilégio concedido a Tolstoi (apesar das reservas feitas à sua concepção "psicologista" da expressão literária ${ }^{51}$ ) assim como a biografia de Wittgenstein parecem confirmá-lo. Idéia que parece confirmada por sua constante tentativa de consagrar-se ao "trabalho manual", ou sua recusa, enquanto "fellow" em Cambridge, de sentar-se à "mesa alta" reservada aos profes- 
sores no restaurante, marcando a necessária distância do corpo discente, assim como declarações como: "Será revolucionário aquele que for capaz de revolucionar-se a si mesmo" 52 .

Nesse contexto, como não lembrar o personagem de Naphta na Montanha Mágica de Thomas Mann? Não é nada insensato supor que o autor criou o personagem tomando como modelo o jovem Lukács ${ }^{53}$. Mas os pontos comuns entre o personagem romanesco e o filósofo vienense são tão impressionantes (anti-Aufklärung, anti-capitalismo romântico, simpatia pelo misticismo cristão supostamente original) que não podemos deixar de fazer a comparação. Sobretudo porque, graças a isso, podemos perceber uma diferença crucial entre as fisionomias semelhantes e a singularidade da de Wittgenstein. De fato, são muitos os textos em que Wittgenstein, apesar de seu catastrofismo, expressa uma certa distância ante o espírito da Tragédia. Uma certa perplexidade ou hesitação face a Shakespeare, remete, talvez, à neutralização que opera da dimensão política da Tragédia. Essa dimensão coloca Wittgenstein no pólo oposto ao de Naphta, para quem a dimensão trágica da Política está em primeiro plano. Dois exemplos: em 1929, Wittgenstein escreve: “A Tragédia consiste em que a árvore não se dobra, mas rompe. A tragédia é coisa não judia. Mendelssohn é, sem dúvida, o compositor menos trágico" 54 ; três anos depois, retomando o tema diz: "Neste mundo (o meu) não há tragédia..."55

Para concluir estas considerações desordenadas (ou demasiadamente "livres") a respeito de Wittgenstein em seus escritos sobre a cultura e o valor, vou apoiar-me sobre um curto ensaio de G.H. von Wright ("Wittgenstein e seu tempo"56), visando um aspecto que me parece importante. Segundo von Wright, não se pode duvidar da ligação interna entre as concepções centrais da filosofia de Wittgenstein - as idéias de "jogo de linguagem", de "forma de vida", de "ver como", da natureza e da origem dos problemas filosóficos - e a recusa da sociedade industrial. Como para nós, trata-se, nesse ensaio, de mostrar que as reflexões sobre a Cultura são algo mais do que uma periferia pouco importante da obra ou mesmo externa a ela; aqui, como na relação entre a "interioridade" da consciência e a "exterioridade" do comportamento publicamente observável, o pensamento de Wittgenstein suprime o dualismo - periferia e núcleo estão em continuidade estrita, como as "duas faces" de uma superfície que se revelam como uma única face no anel de Moebius. 
Subscrevendo inteiramente o raciocínio de von Wright, gostaria simplesmente de, para terminar, acrescentar-lhe apenas uma nuança. Para fazê-lo, dar-lhe-emos, como é necessário, a palavra: de um lado, von Wright nega que a concepção de Wittgenstein sobre a filosofia ambicione valer para todas as situações históricas do pensamento; de outro, admite que Wittgenstein se reconhecia, de algum modo, como "herdeiro" da tradição da filosofia e admitia, assim, uma certa continuidade entre sua obra e o passado da filosofia. Afirma igualmente que não se pode ignorar a consciência histórica de Wittgenstein, assim como sua antipatia pela idéia de uma Philosophia perennis. E von Wright acrescenta que, se aceitássemos tal idéia, a relação entre o pensamento e o presente não poderia ser mais do que contingente ou psicológica. Nas suas palavras: "Pois, nesse caso, a reivindicação implicaria que toda boa filosofia iria de par com uma cultura que declina. O que é manifestamente falso, as grandes filosofias indicam o ápice de uma cultura ou, no máximo, o começo de seu declínio. Mas Wittgenstein nunca reivindicou nada parecido. Sua concepção de filosofia alia-se a uma 'Form der Betrachtung' (forma de reflexão) da civilização contemporânea. Isso é tudo o que devemos admitir" 57.

O que poderíamos acrescentar a esse enquadramento de Wittgenstein na tradição da filosofia? Pelo menos apontar duas maneiras diferentes de vê-lo, a segunda das quais parecendo-nos mais promissora. Na primeira maneira de ver, o enquadramento seria antes uma forma de contraposição: a tradição seria um peso do qual Wittgenstein se daria como tarefa libertar-se, através de uma nova Überwindung da metafísica. $\mathrm{Na}$ segunda, Wittgenstein seria alguém que recupera, mesmo sem disso se aperceber necessariamente (talvez por falta de interesse histórico-filológico), o próprio espírito da filosofia antiga, recoberto e esquecido pelo destino do pensamento nos tempos modernos ${ }^{58}$. Duas vias, ou melhor, duas atitudes que nos permitiriam ver ou interpretar de maneiras opostas um mesmo texto, como aquele de 1947, onde Wittgenstein opõe-se à frieza, à "estupidez", à natureza cinzenta e pálida da Weisheit para promover a paixão da fé onde a chama da vida está presente ou não é dissimulada ${ }^{59}$. Sem dúvida, a palavra Weisheit não tem aqui o sentido que lhe é comumente atribuído, compreendida por oposição à ciência, ao puro saber ou ao conhecimento racional fundado no absoluto ${ }^{60}$. Pelo contrário. 
Mas isto não impede que a frase, como indício do estilo da herança assumida ou recusada por Wittgenstein, muda de sentido de acordo com a visão que tivermos da filosofia grega. Se virmos esta com os olhos de Heidegger, a frase de Wittgenstein nos convida à tarefa da Abbau (demolição ou "desconstrução", para falar como o outro) da Metafísica, mesmo se nessa operação o pretendido "ultrapassamento" ficar muito próximo do simples retorno ao ceticismo. Lida com os olhos de Pierre Hadot, pelo contrário, a frase de Wittgenstein nos remete ao que há de mais essencial na filosofia grega: a idéia de vida feliz que, só ela, justifica a atividade filosófica, o amor da sabedoria.

Talvez possamos acrescentar algo mais. Não parece impensável que essas duas vias aparentemente divergentes possam enrolar-se sem conflito (mais uma vez, como as duas faces da fita do anel de Moebius). Com efeito, entre 30 de julho de 1931 e 13 de setembro do mesmo ano, em menos de dois meses, Wittgenstein acumula reflexões dramatizando as relações entre filosofia grega, tradição filosófica ocidental e espírito judeu. Parece condenar a filosofia ocidental, apontando para sua raíz grega ${ }^{61}$, mas logo em seguida afasta o próprio pensamento grego da tradição filosófica ocidental, que constitui o alvo de sua polêmica, aproximando-o do espírito judeu ${ }^{62}$. O movimento do pensamento é muito diferente, nos tipos ou formas de vida que opõe ou assimila, do de Heidegger que aproxima (até mesmo em suas etimologias, onde mostra a semelhança entre as raízes préfilosóficas do vocabulário dos filósofos gregos da etimologia e as raízes do vocabulário alemão) a filosofia grega original do pensamento alemão, abandonando nas trevas exteriores a apropriação latina daquela tradição (Vergessenheit, etc...), mas tem muito de semelhante na sua forma ${ }^{63}$.

\section{IV}

É hora de concluirmos. Com estas observações, embora um pouco disparatadas, pudemos notar a ligação interna entre uma concepção antiAufklärung da Cultura e uma concepção lógico-gramatical da filosofia. $\mathrm{O}$ sombrio diagnóstico do mundo atual é o outro lado da idéia da atividade filosófica como terapia. Uma terapia que pressupõe a Übersicht das regras da prosa que dão forma ao nosso mundo e à nossa vida, que visa à cura 
das câimbras que paralisam nosso pensamento. Uma luta, enfim, com a linguagem, que tem algo a ver com a poesia. Como Wittgenstein repete no início dos anos 30: "A filosofia, para fazê-la direito, deveríamos escrevê-la apenas em poemas". Uma escrita que entra necessariamente em conflito com a relação puramente prosaica ${ }^{64}$ com a linguagem. Como nos versos do maior poeta brasileiro:

"Lutar com palavras

é a luta mais vã.

Entanto lutamos

mal rompe a manhã."

1 Estas "Observações” foram apresentadas em 18 de junho de 2005 no Institut d'Histoire et Philosophie des Sciences et Techniques (C.N.R.S. et Université de Paris I), encerrando a série de conferências Voir le même comme autre coordenada por Antonia Soulez. Iniciada em 2 de abril do mesmo ano, a série contou com conferências pronunciadas por Ian Hacking (Collège de France), Baudouin Jurdant (Univ. de Paris VII), Jean-François Braunstein (IHPST, Univ. de Paris I), Denis Perrin (Univ. de Grenoble), Alain Janik (Innsbruck), Layla Raid (Univ. de Bordeaux), Daniele Moyal-Sharrock (Londres) e Arley Ramos Moreno (Unicamp). Devo a tradução para o português deste texto à gentileza de minha filha Raquel de Almeida Prado. Não poderia deixar de registrar minha gratidão a meus colegas da Universidade Federal de São Carlos, Débora Morato Pinto e Bento Prado Neto, pela leitura atenta e pelas sugestões para melhorá-lo. Devo acrescentar que esta conferência retoma e tenta aprofundar um texto anterior, "Wittgenstein: Cultura e Valor", publicado em meu livro Erro, Ilusão, Loucura, ed. 34, 2004, depois.de vir à luz in M. Paiva e M. E. Moreira (orgs.) Cultura, Substantivo Plural, Centro Cultural Banco do Brasil e ed. 34, São Paulo, 1990, pp. 79-105.

2 Cf. a edição por G.H. von Wright de Ludwig Wittgenstein, Vermischte Bemerkungen, acrescida de tradução para o inglês por Peter Winch, sob o título de Ludwig Wittgenstein, Culture and Value, ed. Blackwell, 1998. A primeira edição é de 1977.

${ }^{3}$ Não resisto à tentação de lembrar aqui duas anedotas. A primeira refere-se a Gérard Lebrun, logo após sua chegada ao Brasil, no início dos anos 60; a propósito do debate, tão vivo então, sobre a leitura althusseriana de Marx e de sua insistência sobre o corte que separaria a primeira da segunda concepção da dialética, Lebrun nos dizia com humor: “- É um grande filósofo aquele que tem uma idéia inteiramente nova. Mas ter duas? três? será possível?”. A segunda refere-se a Einstein em sua visita ao Brasil logo após a $2^{\text {a }}$ guerra mundial. Recebido por Austregésilo de Ataíde, da Academia Brasileira de Letras, teria notado que este, enquanto lhe mostrava o Rio de Janeiro, tomava notas em um pequeno caderno que retirava a cada instante do bolso; conta-se que perguntou-lhe então qual seria a razão de tal comportamento e recebeu, como resposta algo como: - "Estou tomando nota das idéias novas que me ocorrem a cada instante; o senhor não faz o mesmo?” Ao que Einstein teria redargüido mais ou

doispontos, Curitiba, São Carlos, vol. 3, n. 1, p.11-36, abril, 2006 
menos nos seguintes termos: "Jamais poderia faze-lo, já que só me ocorreu uma única idéia nova em toda a minha vida".

4 "Sentimento" numa acepção próxima de duas registradas por Antonio Houaiss em seu Dicionário: "faculdade de conhecer, perceber, apreciar..." e "percepção intima, conhecimento imediato, intuição...” [a ênfase das expressões em itálico são de minha responsabilidade - B. P. Jr.].

${ }^{5}$ Creio que Wittgenstein concordaria com Georges Braque quando este afirma que pensamento e raciocínio não são a mesma coisa. Traduzida na linguagem de Wittgenstein, a proposição de Braque seria mais ou menos a seguinte: "Raciocínio (ou cálculo) e pensamento desenrolam-se em tempos diferentes: se podemos raciocinar rapidamente, só podemos pensar (como ler ou escrever - o paradigma de Kraus) muito devagar." De fato, o filósofo chega a dizer em Über Gewissheit (657): "Die Sätze der Mathematik, könnte man sagen, sind Petrefakten"; dizer que as proposições da matemática são pétreas ou petrificadas não caminha na direção indicada? Ou, nas Vermischte Bemerkungen, diz ainda (MS 1252 v: 4.1.1942): "O matemático (Pascal) que admira a beleza de um teorema na teoria dos números; ele se admira diante dela como diante de uma beleza natural. É maravilhoso, diz ele, quão admiráveis propriedades tem o número. É como se estivesse admirando a conformidade a leis de um cristal" [a ênfase do itálico é de nossa responsabilidade - B. P. Jr.]

${ }^{6}$ Cf. MS 1384 a: 18.1.1949, - "Mein eigenes Denken über Kunst \& Werte ist weit desillusionierter, als es das der Menschen vor 100 Jahren sein konnte. Und doch heisst das nicht, dass es deswegen richtiger ist. Es heisst nur, das im Vordergrund meines Geistes Untergänge sind, die nicht im Vordergrund jener waren."

7 Cf. MS 109 204: 6-7.11.1930, - "Dieses Buch ist für diejenigen geschrieben, die dem Geist in dem es geschrieben ist freundlich gegenüberstehen."

8 Cf.J.J. Rousseau Roussean juge de Jean-Jacques, Oeuvres Complètes, vol. I, Paris, Gallimard, col. de la Pleiade, p. 668. Ao lado de Rousseau, neste contexto, poderíamos pensar em Nietzsche, especialmente no subtítulo de Assim falava Zaratustra: "Um livro para todos e para ninguém".

${ }^{9}$ Cf. MS 109 204: 6-7.11.1930, - "Dieser Geist ist, glaube ich, ein anderer als des Stromes der grossen der europäischen und amerikanischen Zivilisation. Der Geist dieser Zivilisation dessen Ausdruck die Industrie, Architektur, Musik, der Faschismus \& Socialismus unserer Zeit ist, ist ein dem Verfasser fremder \& unsympathischer Geist."

10 Cf. o MS 112 46:14.10.1931, onde é dito:"O trabalho em filosofia - como o trabalho em arquitetura em vários aspectos - é na realidade mais um trabalho sobre si mesmo. Sobre sua própria concepção (Auffassung). Sobre como se vê as coisas (E sobre o que se espera delas)."

11 MS 109 204: 6-7.11.1930, - "Dies ist kein Werturteil. Nicht als ob ich nicht wüsste dass was sich heute als Architektur ausgibt nicht Architektur ist \& nicht als ob er dem, was moderne Musik heisst, nicht das grösste Misstrauen entgegenbrächte (ohne ihre Sprache zu verstehen), aber das Verschwindem der Künste rechtfertig kein absprechendes Urteil über eine Menschheit."

12 Idem: "Denn echte \& starke Naturen wenden sich eben in dieser Zeit von dem gebiet der Künste $a b$ \& anderen Dingen zu \& der Wert des Einzelnen kommt irgendwie zum Ausdruck." Notemos, neste texto, a passagem de uma forma particular de humanidade

doispontos, Curitiba, São Carlos, vol. 3, n. 1, p.11-36, abril, 2006 
(...eine Menscheit) para o indivíduo na sua singularidade (...des Einzelnen...) a que retornaremos adiante.

13 Como Ivan Kiréievski, A. A. Khomiakov, K. Aksakov e Y. Samarine; cf., a próposito, o capítulo II do livro de N. O. Losski Histoire de la Philosophie Russe, des origines à 1950. Payot, Paris, 1954.

14 Cf. meu prefácio "Ciência Política e Revolução” ao livro de Célia N. Galvão Quirino Dos Infortúnios da Igualdade ao Gozo da Liberdade, ed. Discurso Editorial/FAPESP, S. Paulo, 2001, pp. 11-21.

15 Cf. MS 109 204: 6-7.11.1930: - "Ob ich von dem typischen westlischen Wissenschaftler verstanden oder geschätzt werde, ist mir gleichgültig, weil er den Geist, in dem ich schreibe, doch nicht versteht".

16 Cf. MS 131 66c: 19.8.1946: - "Denn alles, was ich meinen kann, ist doch nur, dass die Bombe das Ende, die Zerstörung eines grässlichen Übels, der ekelhaften, seifenwässrigen Wissenschaft, in Aussicht stellt."

17 Cf. MS 111 119: 19.8.1931, - "Denn da wird dann alles, was für das Urbild der Betrachtung wahr ist nolens volens auch von dem Objekt worauf wir die Betrachtung anwenden behauptet; \& behauptet "es müsse immer...".

18 Já aproximamos, acima, Wittgenstein de Merleau-Ponty, a propósito do caráter necessariamente indireto da linguagem da filosofia e da arte. Aqui é preciso notar que Übersehen nada tem a ver com a visão de sobrevôo a que Merleau-Ponty se opõe, pelo contrário, como se pode ver pela conclusão de nossa frase. Essa aproximação é certamente rara; a meu conhecimento só ocorre no livro Wittgenstein and Metaphor, New and Revised.Edition, Humanities Press, New Jersey, 1996, de Jerry H. Gill, que publicou pela mesma editora, em 1991, MerleauPonty and Metaphor. Num espírito diferente do de Jerry H. Gill - ou numa maneira diversa de ver o uso filosófico da metáfora -, retomei recentemente contra meu amigo Gérard Lebrun tal aproximação em minha conferência "Gérard Lebrun et le Devenir de la Philosophie" (feita em Nice, junho de 2005; sua tradução para o português será publicada pela revista Discurso): aí percorro a contra-mão a oposição que Lebrun crê ser subjacente à convergência entre os dois filósofos que usam, de maneira inteiramente independente, já que cada um não podia conhecer os textos quase idênticos do outro; refiro-me às frases de ambos em que dizem que filosofar é perguntar-se “onde estou?”. Impossível aproximar fenomenologia e análise gramatical? Talvez não, sem chegar ao exagero de Foucault que dizia em São Paulo (em 1965): "Il faut être une mouche aveugle pour ne pas voir que la philosophie de Heidegger et celle de Wittgenstein sont une seule et même philosophie."

19 Cf. a Introdução que Luis Henrique fez à sua tradução do Tractatus, Edusp, 1993. No ensaio "O relativismo como contraponto" (vide meu livro Erro, ilusão, loucura, ed. 34, 2004, pp.199223) procurei dar início a uma exploração do campo aberto por essa bela frase. Sublinhemos que, em 1923, Ortega y Gasset já defendia, em El Tema de Nuestro Tiempo (Revista de Occidente, Madrid, Colección 'El Arquero', 14ª ed., 1961), uma nova óptica, que se colocaria para além da oposição entre racionalismo e relativismo, sob o título de Perspectivismo, que transparece no famoso "Eu sou eu e minha circunstância". Todavia, ao contrário de Wittgenstein, esse perspectivismo parece aí fundado numa instância quase "epistemológica", como trans-

doispontos, Curitiba, São Carlos, vol. 3, n. 1, p.11-36, abril, 2006 
parece no uso da "relatividade" de Einstein tanto contra o absolutismo do racionalismo clássico quanto contra todas as formas de subjetivismo ou de relativismo. É certo que no Nachlass de Wittgenstein podemos encontrar um uso da teoria de Einstein (a que tive acesso graças a Bento Prado Neto) que parece ir na mesma direção que o raciocínio de Ortega y Gasset; mas jamais poderíamos reencontrar na obra do vienense a continuidade que o "raciovitalismo" do espanhol impõe entre filosofia e ciência ou entre vida e ciência. Quando Wittgenstein diz, no Nachlass que, com ele, temos uma espécie "teoria da relatividade da linguagem", fala de uma analogia ou de um ar de família que, como no caso do "comparatismo" cultural, próximo do de Spengler, não permite a passagem "do paradigma ao objeto", proíbe a idéia de uma fundação científica de uma "visão" filosófica (para os textos em pauta do Nachlass, o leitor pode buscar as referências a Einstein e a teoria da relatividade na edição dos manuscritos pela Bergen Eletronic Edition. Basta lembrarmos, em contraponto, que Ortega y Gasset chega a lamentar a tendência de Einstein a minimizar ou a suprimir a idéia de causalidade no interior de sua teoria, numa afirmação que marcha a contrapelo do pensamento de Wittgenstein, para quem o conceito de causalidade está longe de ser central. Na verdade é bem o contrário o que ocorre, como diz a frase que fecha a proposição 5.1361: "A crença no nexo causal é a superstição". A tradução do amigo Gilles-Gaston Granger, ao colocar "est un préjugé", parece diminuir a ênfase do original, que transparece (tal, pelo menos, é minha impressão) na tradução de outro amigo, Luis Henrique Lopes dos Santos, que acabamos de citar; aí sublinha-se o artigo definido - "é a superstição".

20 Denunciado injustamente por Cavaillès nos anos 30, que se deixa levar, como dissemos alhures, pelo tom aparentemente "pré-socrático" do início do Tractatus, que ignora o estilo das proposições em 1 como ponto de partida de um argumento de estilo transcendental; - Como devem ser as coisas para que possamos falar delas de maneira falsa ou verdadeira?.

21 A proposição 7, que diz: "Sobre aquilo de que não se pode falar, deve-se calar", lança nova luz retrospectivamente sobre a afirmativa proposição 1 que diz: "O mundo é tudo que é o caso". Com ela não se encerra o Tractatus, pelo contrário com ela se reinicia a leitura do livro, a escalada da escada que depois poderemos jogar fora.

22 Cf. Über Gewissheit, 422: - "Ich will also etwas sagen, was wie Pragmatismus klingt. // Mir kommt hier eine Art Weltanschauung in die Quere".

${ }^{23} \mathrm{E}$, de fato, Wittgenstein procura destruir a idéia de adaequatio, como, por exemplo, em 215 de Über Gewissheit: "Aqui vemos que a idéia de 'concordância com a realidade' ('Übereinstimmung mit der Wirklichkeit') não tem nenhuma aplicação clara”.

24 Tradução de Álvaro Cabral, Editora campus, Rio de Janeiro, 1991.

25 Que se exprime claramente na valorização da misteriosa especificidade da cultura austríaca na seguinte frase: "Creio que o que há de bom na Áustria (Grillparzer, Lenau, Bruckner, Labor) é particularmente difícil de compreender. É, num certo sentido, mais subtil de todo o resto e sua verdade jamais está do lado da verossimilhança”" (MS 107184 c: 7.11.1929..

26 Cf. MS 107 156c: 10.10.1929, - "Ich denke oft darüber, ob mein Kulturideal ein neues, d. h., ein zeitgemässes, oder eines aus der Zeit Schumanns ist. Zum mindesten scheint es mir eine Fortsetzung dieses Ideals zu sein und zwar nicht die Fortsetzung die es damals tatsächlich erhalten hat. Also unter Ausschluss der zweiten Hälfte des 19. Jahrhunderts”.

doispontos, Curitiba, São Carlos, vol. 3, n. 1, p.11-36, abril, 2006 
27 A civilização atual.

28 Cf. MS 13618 b; 21.12.1947, - "Einmal wird vielleicht aus dieser Zivilisation eine Kultur entspringen./ / Dann wird es eine wirkliche Geschichte der Erfindungen des 18, 19, 20 Jahrhunderts geben, die voll von tiefem Interesse sein wird”.

${ }^{29}$ Editora UFRJ, Coleção Philosophia Analytica, Rio de Janeiro, 2003.

30 Bergson é referido explicitamente por Wittgenstein em duas ocasiões do Nachlass a propósito da compreensão do funcionamento da linguagem (cf. Item 109, p. 197 e Item 211, p.165, respectivamente escritos em 2 de novembro de 1930 e em 7 de fevereiro de 1931), mas, sobretudo, em tais notas como no item 105 (manuscrito de 1929), o que está pressuposto é que a linguagem "pertence a um sistema" tal que não pode haver uma linguagem capaz de descrever o fenômeno em sua duração ou temporalidade. Para Bergson, também, a vocação "espacial" da linguagem proíbe-lhe aderir às ondulações qualitativas da duração; mas para Bergson também, como para Wittgenstein, a adesão silenciosa ao fenômeno que resulta de uma conversão do olhar só é possível no limite da linguagem, que jamais é descartada enquanto tal. Nas Vermischte Bemerkungen, diz-nos o autor: "Isocronismo do relógio e isocronismo da música. Não são de modo algum os mesmos conceitos.”(Cf. MS 13812 a: 30.1.1949; notemos que em sua tradução - edição bilíngüe ed. Por T.E.R., 1984 - Gerard Granel, inadvertidamente põe no original alemão a palavra Zeitlichkeit em lugar de Zeitgleichheit ; confessemos, todavia, que uma diferença de essência entre duas formas de isocronismo implica necessariamente a diferença uma heterogeneidade essencial entre duas formas de temporalidade....Acrescentemos que, se Von Wright conta que Wittgenstein dizia que, como filósofo, Bergson era "mau arquiteto", é preciso compreender que sugeria que o francês não dava a forma adequada (em sua escrita) a suas boas intuições; ou ainda que Bergson poderia responder que Wittgenstein era "mau compositor", não exprimindo musicalmente, como deveria, suas "visões” tão precisas.

31 Cf. 6.521: "Percebe-se a solução do problema da vida no desaparecimento desse problema (não é por essa razão que as pessoas para as quais, após longas dúvidas, o sentido da vida se faz claro não se tornaram capazes de dizer em que consiste esse sentido?)"; e 6.522: "Há por certo o inefável. Isso se mostra, é o Místico".

${ }^{32}$ Ver, acima, a nota 18.

33 Cf. MS 13651 a:3.1.1948, - “Beim Philosophieren muss man in’s alte Chaos hinabsteigen, \& sich dort wohlfühlen".

34 Lembremo-nos como Wittgenstein subverte a noção de fundamento, dizendo que, ao contrário do que se pensa, é o edifício que sustenta seu alicerce. Um pouco à maneira de Pascal que fazia dos teoremas da geometria o "fundamento" dos axiomas de que ela parte, para escapar de maneira não aristotélica (e talvez mais sutil do que a do estagirita) à aporia da regressão ao infinito..

35 Conferir Über Gewissheit, \# 612: "Disse que 'combateria' o outro, mas não dar-lhe-ia eu razões? Sim; mas até onde iriam elas? Ao termo das razões, há a persuasão. (pense no que ocorre quando um missionário converte indígenas.)"

36 Sobre a questão da "base" dos jogos de linguagem cf. minha discussão da interpretação de

doispontos, Curitiba, São Carlos, vol. 3, n. 1, p.11-36, abril, 2006 
José Arthur Giannotti no ensaio "Erro, Ilusão, Loucura" no livro de mesmo nome (cf. acima a nota 1). Aí sublinho a justeza da crítica giannottiana às interpretações relativistas de Wittgenstein, bem como sua recusa da saída oferecida por Apel e Habermas. Mas distancio-me do filósofo brasileiro quando este parece, malgrado seu, continuar seguindo a linha dos citados pensadores alemães.

37 “Se a boa ou má volição altera mundo, só podem alterar os limites do mundo, não os fatos; não o que pode ser expresso pela linguagem./ / Em suma, o mundo deve então, com isso, tornar-se a rigor um outro mundo. Deve, por assim dizer, minguar ou crescer como um todo. / / O mundo do feliz é um mundo diferente do mundo do infeliz."

38 Cf acima a nota 10.

39 Cf. a tradução de Helena Martins, Jorge Zahar Editor, Rio de Janeiro, 1997. A propósito, lembrar a seguinte frase:"Como explicar a alguém o que significa "compreender música"? seria nomeando-lhe representações, sensações cinestéticas experimentadas por quem a compreende? Melhor seria apontando os movimentos expressivos (Ausdruckbewegungen) de alguém que a compreende." Esta frase, certamente, não merece uma interpretação "behaviorista".

40 Como estamos distantes aqui do chamado "argumento da linguagem privada"! Contra o peso dado pelos leitores anglófonos de Wittgenstein ao referido "argumento" (assimilando o filósofo a Ryle), bem como seu ao seu suposto anti-cartesianismo, Gordon Baker encerra um de seus ensaios com as seguintes frases: "Et l'importance de l'argument du langage privé n'est pas proportionnelle à celle des philosophes qui énoncent l'idée que Wittgenstein est en train de soumettre à l'examen. La thérapie qu'il vise est beaucoup plus générale que le simple traitement des maladies cartésiennes. La reception parmi les philosophes Anglophones, aussi enthousiaste qu'elle soit, constitue un obstacle qui continue à nous empêcher de profiter de la richesse du legs des Recherches." Quanto às "doenças cartesianas" G. Baker mostra, no mesmo texto, o equívoco de interpretar Wittgenstein como o demolidor de uma tradição, que a ela se opõe como David aos Filisteus, uma vez que Wittgenstein "ne connait pas les oeuvres de Descartes, et par ailleurs il ne pense pas que les confusions philosophiques d'aujourd'hui découlent des péchés que quelques philosophes auraient commis hier." Cf. G. Baker, "La Réception de l'argument du langage privé" in Acta du Colloque Wittgenstein (Collège International de Philosophie, junho de 1988, ed.T.E. R., 1990 - organização de Fernando Gil).

41 Cf. MS 162 b 24 r: 1939-1940, - "Das Genie hat nicht mehr Licht ein andrer, rechtschaffener Mensch - aber es sammelt dies Licht durch eine bestimmte Art von Linse in einen Brennpunkt".

42 Cf. MS 133 2: 23.10.1946, - "Denn Wahnsinn muss man nicht als krankheit ansehen. Warum nicht als eine plötzliche - mehr oder weniger plötzliche - Charakteränderung?”.

43 Basta lembrar a abertura do Discurso do Método: "Le bon sens est la chose du monde la mieux partagée..."

44 Refiro-me, é claro, ao segundo preceito do Discurso do Método ("dividir cada uma das dificuldades que eu examinasse em tantas parcelas quanto possíveis e quanto necessárias fossem para melhor resolvê-las.”) ou à regra $V$ das Regulae. Na nota 24 que apôs à tradução brasileira (de Jacó Guinsburg) do Discurso do Método (na coleção Pensadores da Ed. Abril). Gerard Lebrun remete a idéia de divisão, presente na frase citada do segundo preceito, ao tratamento

doispontos, Curitiba, São Carlos, vol. 3, n. 1, p.11-36, abril, 2006 
mais "técnico" que recebe na primeira parte do Livro III da Geometria, onde ela revela seu sentido mais preciso.

45 Cf., logo acima, a nota 38.

46 Cf. MS 156 b 32 r:ca. 1932-1934, - “Es kommt mir (manchmal) vor als philosophierte ich schon mit einem zahnlosen Mund \& als schiene mir das Sprechen mit einem zahnlosen Mund als das eigentliche, wertvollere. Bei Kraus sehe ich etwas Ähnliches. Statt dass ich es als verfall erkennte".

47 Seis referências ao trágico, três a Shakespeare, e vinte e duas à música. Nove vezes Wittgenstein refere-se à religião no mesmo livro.

48 Reduzidas também talvez não seja uma boa palavra, pois a dimensão ética não é diferente da dimensão estética. Ao contrário de Kierkegaard - que de outro lado aparece sempre como um ponto de referência crucial para Wittgesntein -, aqui estética, ética e religião não constituem três etapas diferentes e sucessivas no caminho da existência, mas uma única esfera: aquela que dá à vida, num só golpe, o seu sentido. Um sentido que não pode ser dito, mas pode ser vivido e expresso.

49 Mais uma vez, Kierkegaard...

50 Wittgenstein seria, como Guimarães Rosa ter-se-ia declarado, um "pagão crente a la Tolstoi”? Cf. o ensaio de Francis Utéza, em seu último parágrafo, Grande Sertão:Veredas, Os recados do Pentagrama, apresentado no Seminário Internacional João Guimarães Rosa, Grande sertão: veredas e Corpo de baile, comemorativo do cinqüentenário da publicação dos dois livros, promovido pelo Instituto de Estudos Brasileiros e pela USP.

51 Em MS 134 106: 5.4.1947, Wittgenstein diz: "poderíamos aprender muito com a falsa teorização de Tolstoi segundo a qual a arte veicula um 'sentimento",,

52 Cf. MS 165 204: 1944, - "Revolutionär wird der sein, der sich selbst revolutionieren kann”.

53 Ao contrário do que afirma taxativamente ${ }^{a}$ Gisselbrecht em seu verbete consagrado a Thomas Mann - na Encyclopédie Philosophique Universelle III, Les Oeuvres Philosophiques (Dictionnaire)2, P.U.F., 1992 - contra todas as evidências tanto literárias quanto diretamente documentais.

54 Cf. MS 10772 c: 1929, - "Die Tragödie besteht darin dass sich der Baum nicht biegt sondern bricht. Die Tragödie ist ewas unjüdisches. Mendelssohn ist wohl der untragischste Komponist."

55 Cf. MS 110 12: "Eine Tragik gibt es in dieser Welt (der meinen) nicht...”.

56 Cf. Georg Henrik von Wright, Wittgenstein, trad. de Élisabeth Rigal, ed.T.E.R., 1986, pp. 215-229.

57 Cf. Georg Henrik von Wright, op. cit., p. 229.

58 Esta segunda via já fora apontada em 1962 por Pierre Hadot; cf. "Jeux de langage et philosophie", Révue de Métaphysique et de Morale, no 67 , pp. 300-313 (reproduzido no livro recém publicado de Hadot, Wittgenstein et les limites du langage, ed.Vrin, 2005).

doispontos, Curitiba, São Carlos, vol. 3, n. 1, p.11-36, abril, 2006 


\section{4}

59 C. MS 134 20:3.3.1947, - "Die Weisheit ist etwas Kaltes, \& insofern Dummes.(der Glaube dagegen, eine Leidenschaft.) Man könnte auch sagen: Die Weisheit verhehlt Dir nur das Leben. (Die Weisheit ist wie kalte, graue asche, die die Glut verdeckt.)

60 Transparente na oposição usual em francês entre science e sagesse.

61 Em MS 111 55: 30.7.1931, podemos ler:"Quando lemos os diálogos socráticos, temos a sensação de uma terrível perda de tempo! Para que esses argumentos que não provam nada e nada esclarecem?”. Em 24 de agosto, talvez pensando no lugar Real atribuído por Whitehead à Platão na história da Razão, Wittgenstein escreve: "Eu leio: 'philosophers are no nearer to the meaning of Realitiy than Plato got...' que estranha situação! Como é singular que Platão tenha podido chegar tão longe! Ou somos nós os incapazes de ir mais longe? Seria porque Platão era tão inteligente?” Na mesma página, Wittgenstein já dissera que essa atualidade de Platão talvez se devesse à injustificada remanência de alguns falsos problemas: "mas aqueles que dizem isso [que a filosofia não fez progresso algum desde os gregos - nota de B. P. Jr.] não compreendem a razão porque as coisas devem ser assim. Ora, essa razão é que a nossa língua permaneceu idêntica a si mesma e que nos desvia em direção das mesmas questões. Enquanto houver um verbo 'ser' que parecer funcionar como funcionam 'comer' e 'beber'...".

62 Já em 13 de setembro de 1931, Wittgenstein escreve (MS 111 195): “Submete-se sempre o judeu, na civilização ocidental, a medidas que não lhe cabem. Que os pensadores gregos não eram nem filósofos no sentido ocidental, nem cientistas no sentido ocidental, que os participantes dos Jogos Olímpicos não eram esportistas e que não se deixam enquadrar em nenhuma disciplina no sentido ocidental, isto é claro para muitos. Mas o mesmo ocorre com os judeus. E na medida em que as palavras de nossa língua [a palavra 'língua' foi conjecturalmente acrescida ao texto por von Wright] aparecem pura e simplesmente como os únicos parâmetros de medida, sempre far-lhes-emos injustiça. Serão sempre superestimados ou subestimados. Assim, Spengler tem razão em não classificar Weiniger entre os filósofos ocidentais”. Mais ainda: no mesmo ano, recorrendo à mesma metáfora com que opusera o frio cinzento da ciência à brasa ardente da fé, Wittgenstein diz em MS 153 a $160 \mathrm{v}$ : "O Judeu é uma região desértica onde, sob uma fina camada de rocha, jaz a chamejante e fluida massa do espírito".

63 Talvez isso nos ajude a compreender os julgamentos algo surpreendentes que os dois filósofos fizeram um sobre o outro. De um lado, Wittgenstein, provavelmente surpreendendo os membros do Círculo de Viena, ao dizer-lhes que compreendia perfeitamente Heidegger, até mesmo seu "Das Nichts nichtet", para eles o paradigma supremo do non-sense. De outro, Heidegger ao dizer que Wittgenstein seria o "Heráclito de nosso tempo", o que, em sua boca, não era pouco dizer.

${ }^{64}$ Esperamos nos demorar, em outra ocasião, sobre o uso (ou os usos) que Wittgenstein faz da palavra prosa. Limitemo-nos, nesta circunstância, apenas a sublinhar que, no vocabulário de nosso filósofo, prosa e poesia jamais se opõem de maneira trivial, como podemos observar na Bemerkung seguinte: "Assim como não posso escrever verso algum, também só posso escrever prosa até certo ponto e não mais.” (MS 134 108: 5.4.1947)

doispontos, Curitiba, São Carlos, vol. 3, n. 1, p.11-36, abril, 2006 


\section{Referências bibliográficas}

Obras de Wittgenstein:

WITTGENSTEIN, L. 1984. Werkausgabe. Ed. Suhrkamp, 1984

(especialmente o oitavo volume, que contém as Vermischte Bemergungen e Über Gewissheit).

1993. Tractatus Logico-philosophicus. Edição

bilíngüe, com tradução e introdução de Luis Henrique Lopes dos

Santos, São Paulo:Edusp.

1993. Tractatus Logico-philosophicus. Tradução de

Gilles-Gaston Granger, Paris: Gallimard.

, L. 1998. Vermischte Bemerkungen / Ludwig

Wittgenstein - Culture and Value. Ed. G. H. von Wright, tradução de

Peter Winch, Blackwell.

, L. 1984. Vermischte Bemerkungen / Remarques

Mêlées, trad. De Gérard Granel, ed.T. E. R.

, L. 1989. Conferencia sobre ética. Tradução de Fina

Mirulés, Ed. Paidós, I.C.E. da Universidad Autónoma de Barcelona.

, L. 2000. Nachlass. Bergen Eletronic Edition.

Diplomatic Transcription. Oxford University Press. The Wittgenstein Trustees. The University of Bergen.

Obras de outros autores:

BAKER, G. 1990. "La réception de l'argument du langage privé" in Acta du Colloque Wittgenstein, ed. T. E. R.

QUIRINO, C.G. 2001. Dos Infortúnios da Igualdade ao Gozo da Liberdade. São Paulo: Discurso/FAPESP.

GLOCK, H-J. 1997. Dicionário Wittgenstein. Trad. De Helena Martins, Rio de Janeiro: Zahar.

HADOT, P. 2005. "Jeux de langage et philosophie", in Wittgenstein et les limites du langage, Paris:Vrin.

HILL, J. H. 1996. Wittgenstein and Metaphor, New Jersey: Humanities Press. 

, 1991. Merleau-Ponty and Metaphor, New Jersey: Humanities

Press.

JANIK, A e TOULMIN, S. 1991. A Viena de Wittgenstein, tradução de Álvaro Cabral, Ed. Campus.

ORTEGA Y GASSET, J. 1961. El Tema de Nuestro Tiempo, Revista de Occidente, Madrid, Col. 'El Arquero', $14^{a}$ edição.

PRADO Jr., B. 2004. Erro, Ilusão, Loucura. São Paulo: ed. 34.

PRADO NETO, B. 2003. Fenomenologia em Wittgenstein: Tempo, Cor e Figuração. col. Philosophia Analytica, ed. da UFRJ.

ROUSSEAU, J.-J. Rousseau juge de Jean-Jacques, Oeuvres Complètes, vol. I da col. de la Plêiade, ed. Gallimard.

WRIGHT, G. H.Von. 1986. Wittgenstein. Tradução de Elisabeth Rigal, ed. T. E. R. 